\title{
Smart Pollution Monitoring for Instituting Aware Traveling
}

\author{
Tanuj Ahuja \\ Bharati Vidyapeeth's College of \\ Engineering \\ A 4, Rohtak Road, \\ Paschim Vihar, \\ New Delhi 110063
}

\author{
Vanita Jain \\ Bharati Vidyapeeth's College of \\ Engineering \\ A 4, Rohtak Road, \\ Paschim Vihar, \\ New Delhi 110063
}

\author{
Shriya Gupta \\ Bharati Vidyapeeth's College of \\ Engineering \\ A 4, Rohtak Road, \\ Paschim Vihar, \\ New Delhi 110063
}

\begin{abstract}
With the advent of urbanization and industrialization, the emission levels of pollutants have since burgeoned. The poor controlling of the emissions of toxic and particulate gasses as well as non-availability of suitable catalytic converters to save the environment from further degrading worsens the quality of air and thus pose severe health risks to the populations. This paper proposes a novel approach in which real-time analytics of pollutant levels in air is performed by using the concept of Internet of Things (IoT) along with Analytics of Things and thereby urging an institution of aware traveling amongst people. The purpose is to provide a solution for healthier living by creating awareness among people about the quality of the air they are breathing and hence enabling them to make better choices regarding their ambiance by practicing activities such as taking a less polluted route to work or buying a house in a healthier area.
\end{abstract}

\section{Keywords}

Internet of Things, Analytics, Cloud Computing, Air Quality Sensors, Gas Sensors, Arduino Uno, Aware Traveling

\section{INTRODUCTION}

Air quality degradation comes as no new problem and a number of steps have been taken to avoid it. The knowledge of the quality of air in immediate environment help people make smarter decisions and choices for their everyday life activities [1]. For example, one can make better decisions about which route to travel from so that he/she is exposed to less pollution or, if a person is asthmatic he/she can buy a home in a place where there is less pollution.

The air quality is not just any other parameter but a salutary creator. Only PREDICTING state or city temperature isn't enough. There is a need to enlighten the individuals by ANALYZING the air quality and providing useful INSIGHTS from town to town, from area to area, from park to park and lastly from human to human[2].

Figure 1 shows the primary and the secondary pollutants in cities.

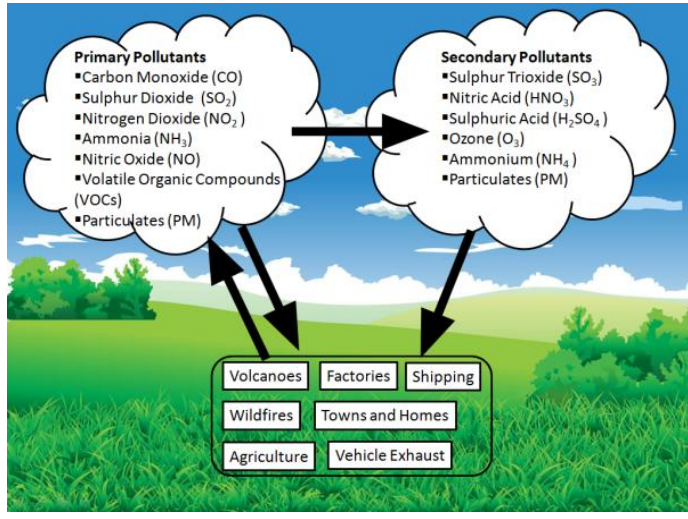

Fig 1- Air pollution in cities [3]

To understand the problem statement more thoroughly, consider the following areas and corresponding air quality drivers:-

- PARKS - The need is to maintain a higher air quality and therefore a lower gaseous particulate density.

- DUMPING GROUNDS- Methane and Plastic levels can be checked for danger threshold limits.

- BURIAL GROUNDS- Phosphorous and Oxygen mixture can cause fitful fires. Such incidents can be reported when a number of buried bodies are significant to ignite phosphorous.

- WATER BODIES- Hydrogen Sulphide danger levels can be monitored to keep water pollution in check.

- INDUSTRIAL AREAS- Various industrial gasses' emission needs to be monitored to ensure that industries are abiding by the standard.

- HOSPITALS- Needs to remain the cleanliest place for obvious reasons, thus there needs to be assurance of a healthy environment.

Realizing the powerful influence which the analysis of air quality at different places plays in promoting awareness in the lives of general public, a device known as 'Smart Weather Box' is created which has the capability to detect the quality of air in the surroundings and thus institutes the concept of aware travelling amongst people. This device works on concept of IOT (Internet of Things). The data is collected using MQ sensors [4]. The data so collected is stored in a cloud API. The API is used to perform analytics on the data and plot the variation in the parts per million (ppm) levels. 
These variations assist to interpret the changes in the air quality level and take decisions. Furthermore, the real-time values are provided to the customers in vicinity in the form of email or popup notifications thereby urging them to indulge into necessary prevention measures.

The paper is organized in 8 sections. Section 2 presents some of the works related to the proposed system which have been practiced off lately. Section 3 briefly describes what Internet of Things technology is. In section 4 , the components used by the system have been described. Continuing it, section 5 discusses the proposed framework and integrating of technologies to create the system. The observations and related results are discussed in section 6. Further, section 7 concludes the paper and future scope is discussed in section 8 .

\section{RELATED WORKS}

Although a varying number of factors affect air quality, there are concrete studies $[5,6,7,8]$ which indicate that the prime contributor of air pollution is transportation. Thus, it becomes of utmost importance especially for metropolitan cities to deal with this problem mainly due to health concerns.

In one such studies, radio frequency identification (RFID) has been demonstrated to address multiple problems such as traffic signal management, environment alerting, vehicle theft identification, accident risk management etc. [5].The method followed allows an RFID tag to be placed on each vehicle which continuously monitors and sends vehicle information to the nearest database, which can be anything from parking lot sensor, toll plaza embedded system or any other RFID tag reader installed at roadside.

As a part of study in [6], a Mobile Discovery Network has been realized to analyze real-time air quality based upon traffic patterns, concentration of various pollutants as well as exposure of pedestrians and travelers to such environments. Both stationary (roadside) and mobile (vehicle) sensors have been inculcated to harness the architecture. This framework was practiced using GUSTO sensor technology in East London with the help of distributed data mining algorithms which help cumulate data from various sensors and help analyze them in real-time as well as plot the pollutant particulate levels on a map using a classified color scheme.

A system proposed in [7] is based on air pollution monitoring in Mauritius by using Wireless Sensor Networks scattered all across the island nation. As with every other country, the country has its own Air Quality Index (AQI) parameters and makes use of aggregation and elimination algorithms to summarize and discard valid and invalid readings respectively.

Another recent study [8] held in Greece made use of solidstate gas indicating sensors as well as piezoelectric traffic density measurement sensors for monitoring vehicular emission pattern over a 24 hours period covering a total of 1200 vehicles and classifying them based upon emissionsignature. The system made use of Secure Digital (SD) card to store electrical signals from the sensors.

\section{INTERNET OF THINGS}

The internet of things or more commonly IoT suggests a simple concept that everyday objects used for different activities can be connected to the internet and also with each other. Everything ranging from cars, machines, appliances and even things like the roads and humans are also a part of the network [9].

The basic infrastructure of IoT consists of three main parts-
- The Thing- Which is mainly a sensor used to catch information

- The Network- Across which the values are transmitted when being sent from IoT to the processing system

- $\quad$ The System- Which processes the data flowing from the system

The overall system is an event-driven architecture, made in bottom-up fashion based upon real-time context of operations and processes. The Internet of Things doesn't comprise of a new class of systems. Rather it helps achieve the incremental development path for extending existing Information \& Communication Technology Systems [10]. Thus, it becomes even more important to study it as a process and not a product.

Another point of concern is that IoT is populated by a humungous number of heterogeneous networked devices, which are characterized by generation of tons of big data, especially in unstructured form. This data collected is of no use unless we are able to understand and analyze it [11]. Given the consensus amongst people regarding the importance of big data analytics, and the fact that IoT mining is still relatively new, the term Analytics of Things comes into picture to help gauge some useful insights.

\section{COMPONENTS USED IN THE SYSTEM}

\subsection{Sensors}

\subsubsection{MQ-3 Gas Sensor}

It is an $\mathrm{SNO}_{2}$ heating sensor which is highly sensitive to alcohol in particular. Apart from this, it is also slightly sensitive to Benzene components. The stable and long life of these sensors makes them a rigid choice for this project. It is relatively useful and suitable as a Breathalyzer [12] and an alcohol checker.

The values are measured in particles per million (ppm) and indicated as either ppm or $\mathrm{mg} / \mathrm{L}$. ( $0.4 \mathrm{mg} / \mathrm{L}=220 \mathrm{ppm}$ in air) . The MQ3 consists of 6 pins as shown in the diagram below. In this two of the pins are used for heating and two are used for connecting to Vcc and Gnd. The heating tube is made of aluminum oxide and is covered by $\mathrm{SnO}_{2}$ [13]. When the current passes through the tube it gets heated up and the tin dioxide, because of heating acts like a semiconductor. This allows the flow of a large number of electrons and hence increases the current flow. When alcohol molecules come near the sensor, the ethanol burns into acetic acid and then more current is produced. Because of the current change, we get the different values of the sensor.

The figure 2 and figure 3 give the structure diagram and the circuit diagram of MQ-3 respectively.

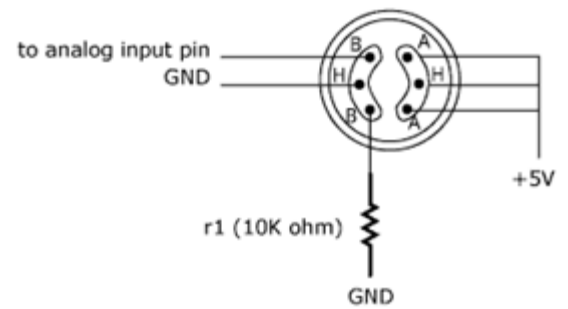

Fig 2- MQ3 Structure Diagram [13] 


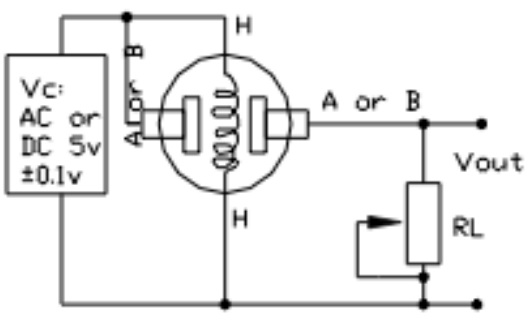

Fig 3- MQ3 Circuit Diagram [13]

The structural components and materials used in various part of the sensor are tabulated in table 1 .

Table 1. MQ3 Structural Components [13]

\begin{tabular}{|c|c|c|}
\hline Sno. & Parts of Sensor & Materials \\
used
\end{tabular}

Also, in a sensor, sensitivity is defined as the change in the output of the sensor being observed to the change in the parameter being measured.

Hence, the sensitivity characteristics of MQ3 are stated in table 2 .

Table 2. MQ3 Sensitivity Characteristics [13]

\begin{tabular}{|l|l|l|}
\hline SNo. & Parameter Name & Technical Parameter \\
\hline 1. & Sensing Resistance(Rs) & $1 \mathrm{M} \Omega-8 \mathrm{M} \Omega$ \\
\hline 2. & Preheat Time & Over 24 hours \\
\hline 3. & $\begin{array}{l}\text { Standard Detecting } \\
\text { Condition }\end{array}$ & $\begin{array}{l}\text { Vcc: } 5 \mathrm{~V} \pm 0.1 \\
\text { Temp: } 20 \pm 2 \\
\text { Humidity: } 65 \% \pm 5 \%\end{array}$ \\
\hline 4. & Concentration Slope rate & $\leq 0.6$ \\
\hline 5. & $\begin{array}{l}\text { Detection concentration } \\
\text { slope }\end{array}$ & $\begin{array}{l}0.05 \mathrm{mg} / \mathrm{L}-10 \mathrm{mg} / \mathrm{L} \\
\text { Alcohol }\end{array}$ \\
\hline
\end{tabular}

\subsubsection{MQ-135 Gas Sensor}

The primary purpose of this sensor is to measure air quality for both indoor (offices/buildings) as well as outdoor (parks/dump yards) etc. areas especially in terms of providing particles per million (ppm) value for $\mathrm{NH}_{3}, \mathrm{NO}_{\mathrm{x}}$, alcohol, Benzene, smoke, $\mathrm{CO}_{2}$ etc [14].

The features which make them rigid and stable working machines are a simple driver circuit accompanied by a long life of working, a wide detecting scope and fast and high sensitivity response time [15].The different sensitivity characteristics of MQ-135 are mentioned in table 3 and the various material used in making different parts of the sensor are mentioned below in table 4 . Also, the figure 4 represents the circuit of MQ-135.

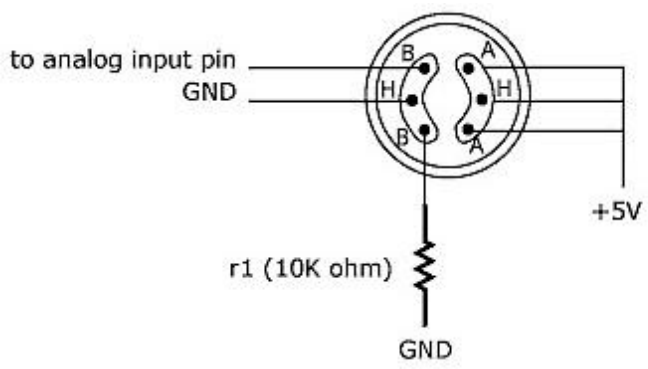

Fig 4:MQ-135 Circuit [15]

Also, the sensitivity characteristics of MQ-135 are as follows:

Table 3. MQ135 Sensitivity Characteristics [15]

\begin{tabular}{|l|l|l|}
\hline SNo. & Parameter Name & Technical Parameter \\
\hline 1. & Sensing Resistance(Rs) & $30 \mathrm{~K} \Omega-200 \mathrm{~K} \Omega$ \\
\hline 2. & Preheat Time & Over 24 hours \\
\hline 3. & $\begin{array}{l}\text { Standard } \\
\text { Condition }\end{array}$ & $\begin{array}{l}\text { Vec: } 5 \mathrm{~V} \pm 0.1 \\
\text { Temp: } 20 \pm 2\end{array}$ \\
& Humidity: $65 \% \pm 5 \%$ \\
\hline 4. & Concentration Slope rate & $\leq 0.65$ \\
\hline 5. & $\begin{array}{l}\text { Detection concentration } \\
\text { slope }\end{array}$ & $\begin{array}{l}10 \mathrm{ppm}-300 \mathrm{ppm} \mathrm{NH}_{3} \\
10 \mathrm{ppm}-1000 \mathrm{ppm} \\
\text { benzene } \\
10 \mathrm{ppm}-300 \mathrm{ppm} \\
\text { Alcohol }\end{array}$ \\
\hline
\end{tabular}

Table 4. MQ135 Structural Components [15]

\begin{tabular}{|c|c|c|}
\hline Sno. & Parts of Sensor & $\begin{array}{c}\text { Materials } \\
\text { used }\end{array}$ \\
\hline 1. & Gas sensing layer & $\mathrm{SnO}_{2}$ \\
\hline 2. & Heater Coil & $\mathrm{Ni}-\mathrm{Cr}$ alloy \\
\hline 3. & Electrode & $\mathrm{Au}$ \\
\hline 4. & Electrode Line & $\mathrm{Pt}$ \\
\hline 5. & Clamp Ring & $\mathrm{Ni} \mathrm{Copper} \mathrm{plating}$ \\
\hline 6. & Tube Pin & $\mathrm{Ni}$ Copper plating \\
\hline 7. & Anti-explosion network & $\begin{array}{c}\text { Stainless } \\
\text { steel }\end{array}$ \\
\hline 8. & Tubular Ceramic & $\mathrm{Al}_{2} \mathrm{O}_{3}$ \\
\hline 9. & Resin Base & $\mathrm{Bakelite}^{2}$ \\
\hline
\end{tabular}

\subsection{Arduino}

It is an open-source hardware and software microcontrollerbased platform system which can be used along various communicating and sensing technologies.

The ease of use while reading serial data and the concept of extensibility makes it more attractive for the user community. It has its inbuilt libraries for performing various operations ranging from transmission over wireless as well as wired media. It thus becomes a go-to choice for Internet of Things 
projects.

Most Arduino boards are calibrated to work at a linear regulation of $5 \mathrm{~V}$ and $16 \mathrm{MHz}$ clock speed. Arduino Uno, the most common of the family uses the concept of USB-to-serial conversion and has 6 analog pins and 14 digital I/O pins [16, 17]. To increase the voltage readings as is for some projects which have higher loads, a male port is provided for connecting external voltage adapter (which is the case with discussed implementation). Arduino Uno's top view is given in figure 5 .

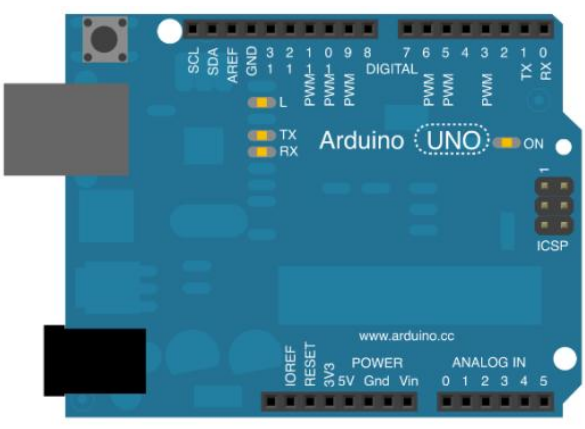

Fig 5: Arduino Uno

\subsection{Wifi Shield}

It works on a simple concept of mounting the shield over Arduino board and connecting it to a wifi network over which it will pass parameters received by the board $[18,19]$. To do this, the SSID and PASSWORD of communicating wifi is required.

\section{PROPOSED FRAMEWORK}

\subsection{System Architecture}

The framework used in discussed problem is shown in figure $6-$

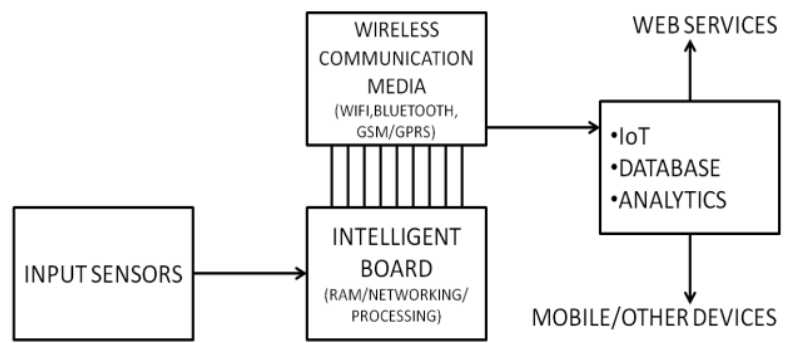

Fig 6: IoT Framework for proposed problem

The input sensors, in this case, two MQ-135 (for measuring Air Quality) and one MQ-3 (Alcoholic gas sensor) are the Thing. They are calibrated to capture on the fly data from surroundings. The microcontroller (Arduino Uno) is used to process the sensor value serially which is transmitted over a provided wifi connection using Ethernet Shield.

A cloud vendor, thethings.io [20] is chosen which acts as a platform for database storage and real-time analytics. Such a dashboard provides end-to-end business analytics solution indicating the activities occurring throughout the time scope.

By analyzing the collected data using Internet of Things, awareness can be spread among people by sending them salutary messages through e-mail/SMS that update them about which route is less polluted, which area requires serious maintenance, industrial v/s residential pollution statistics, healthy surrounding analysis and so on.

\subsection{Integration of Technologies}

The three sensors ( 2 X Air Quality and 1 X Alcoholic Sensor) were surmounted on a breadboard and interfaced with an Arduino Uno Version 3. The two air quality sensors have been used to calibrate more accurate results since different electronic components tend to have different error ratings and MQ3 sensor was used to gauge Alcoholic level. The ANALOG input (AO) was observed over digital pins (DO). Furthermore, Vcc and GND were respectively connected to provide $+5 \mathrm{~V}$ and $0 \mathrm{~V}$ supply.

The same calibration was practiced for the above four mentioned ports of all the three sensors. Figure 7 shows sensor MQ135 and sensor MQ3.

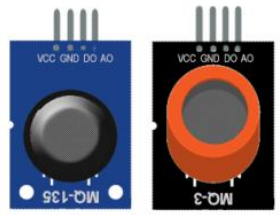

Fig 7: MQ135 and MQ3

The real-time readings were transferred from microcontroller to the free cloud service provider (thethings.io) over wi-fi using Ethernet Shield mounted over Arduino board.

For this, the API KEY for the cloud dashboard as well as transferring wi-fi space credentials (SSID, PASS, SECURITY) were provided.

The interfacing of the circuit with the internet is shown in figure 8 .

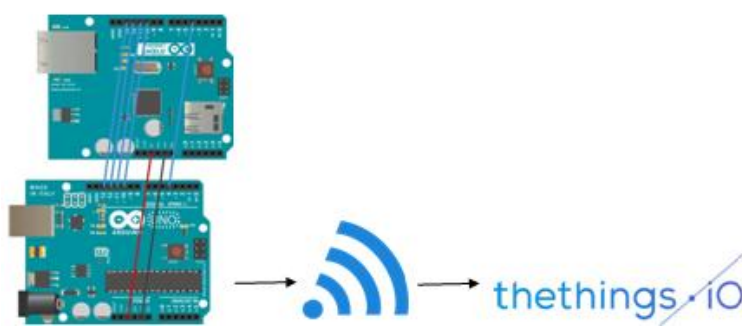

Fig 8: Interfacing circuit with the internet

The data collected was visualised on the cloud dashboard with line graphs and logs indicating both real-time and historical values. Other ways provided by the chosen cloud vendor to represent data are gauges, pie charts, live data reading, bar graph, $\log$ values etc.

The travelers and pedestrians in the region under monitoring were notified about air quality (if the PPM levels cross the threshold) in the form of emails/SMS and were also provided with an alternative route, thus reducing further crowding of polluted area.The circuit diagram of the proposed system is given in figure 9 . 


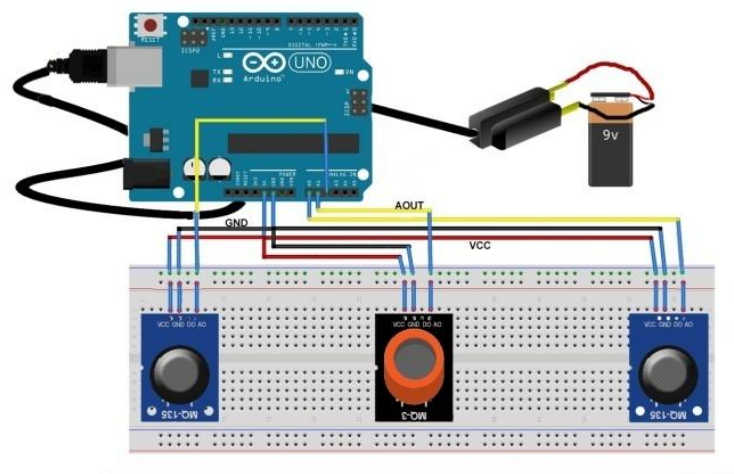

Fig 9: Basic Component Placement

Figure 10 depicts the model of the entire system after the technologies were integrated and Figure 11 shows the top view of the system.

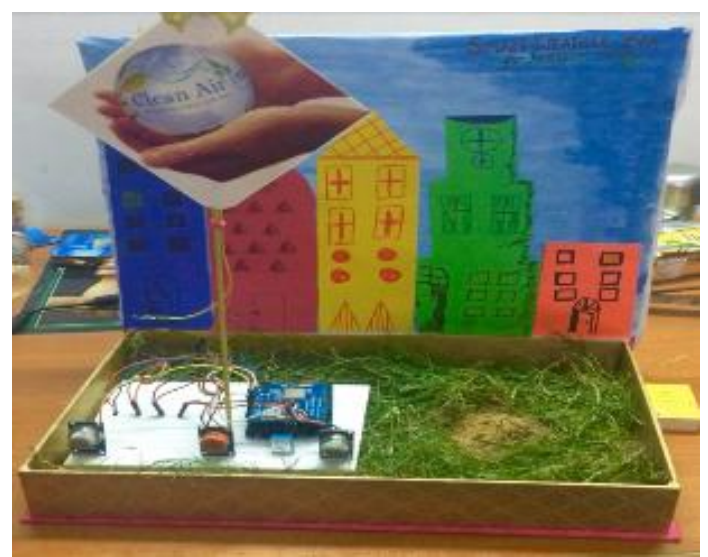

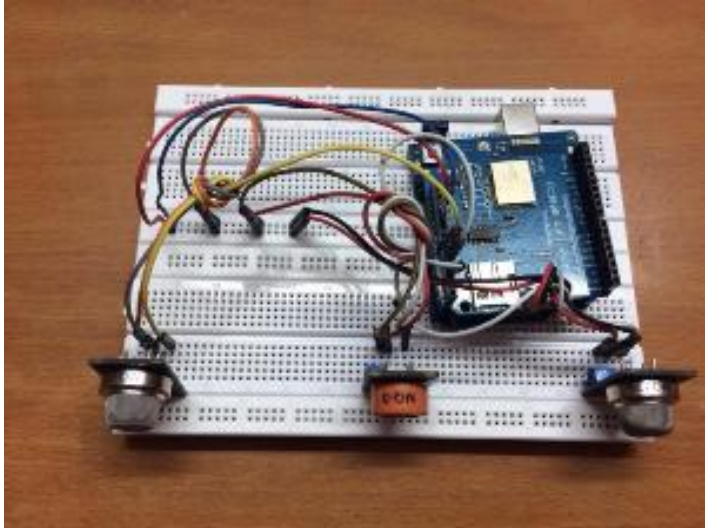

Fig 11: Experimental Setup (Top view)

\section{OBSERVATIONS \& RESULTS}

To understand the efficacy of the system, the data at four locations where air monitoring becomes a need was gathered. These four places are Open Dumping Yard (J Block,Rajouri Garden, New Delhi,India), Industrial Area (Mayapuri factories on outskirts of Rajouri Garden,New Delhi,India), Park(Madhav Park,Rajouri Garden,New Delhi,India) and School(Cambridge Foundation School, Rajouri Garden,New Delhi,India). The date of observation was 2nd May 2016.

The three sensors are named as follows-

- A0- Air Quality Sensor 1

- A1- Alcohol Sensor

- A2- Air Quality Sensor 2

The Table 5 is an indication of readings recorded.

Fig 10: Prototype of the system

Table 5: Indication of Air Quality \& Alcohol level at four different locations

\begin{tabular}{|l|l|l|l|l|}
\hline & Dump Yard & Industrial Area & Park & School \\
\hline $\begin{array}{l}\text { Air Quality } \\
(\mathrm{ppm})\end{array}$ & 246 & 202 & 186 & 197 \\
\hline $\begin{array}{l}\text { Alcohol Level } \\
(\mathrm{ppm})\end{array}$ & 112.15 & 74.18 & 59.71 & 75.22 \\
\hline
\end{tabular}




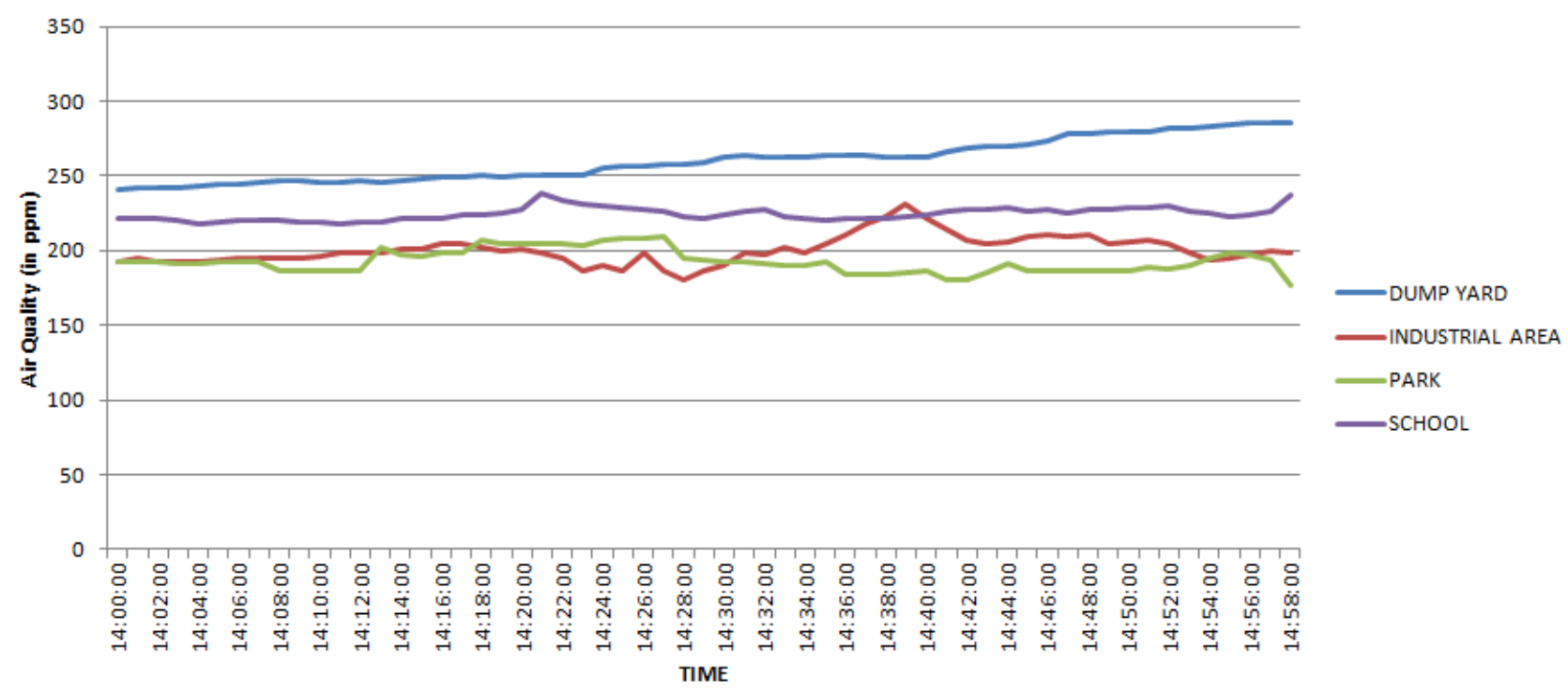

Graph 1: Air Quality as indicated by A0 sensor for the four monitored places

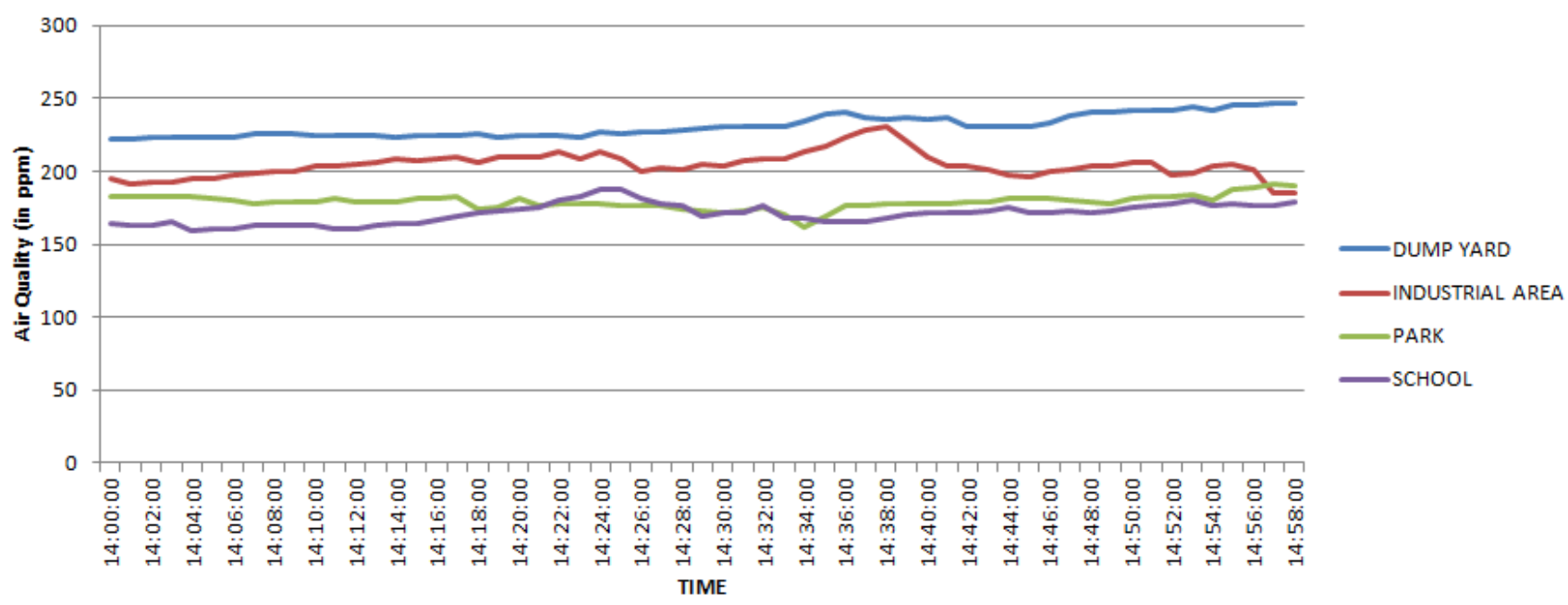

Graph 2: Air Quality as indicated by A2 sensor for the four monitored places

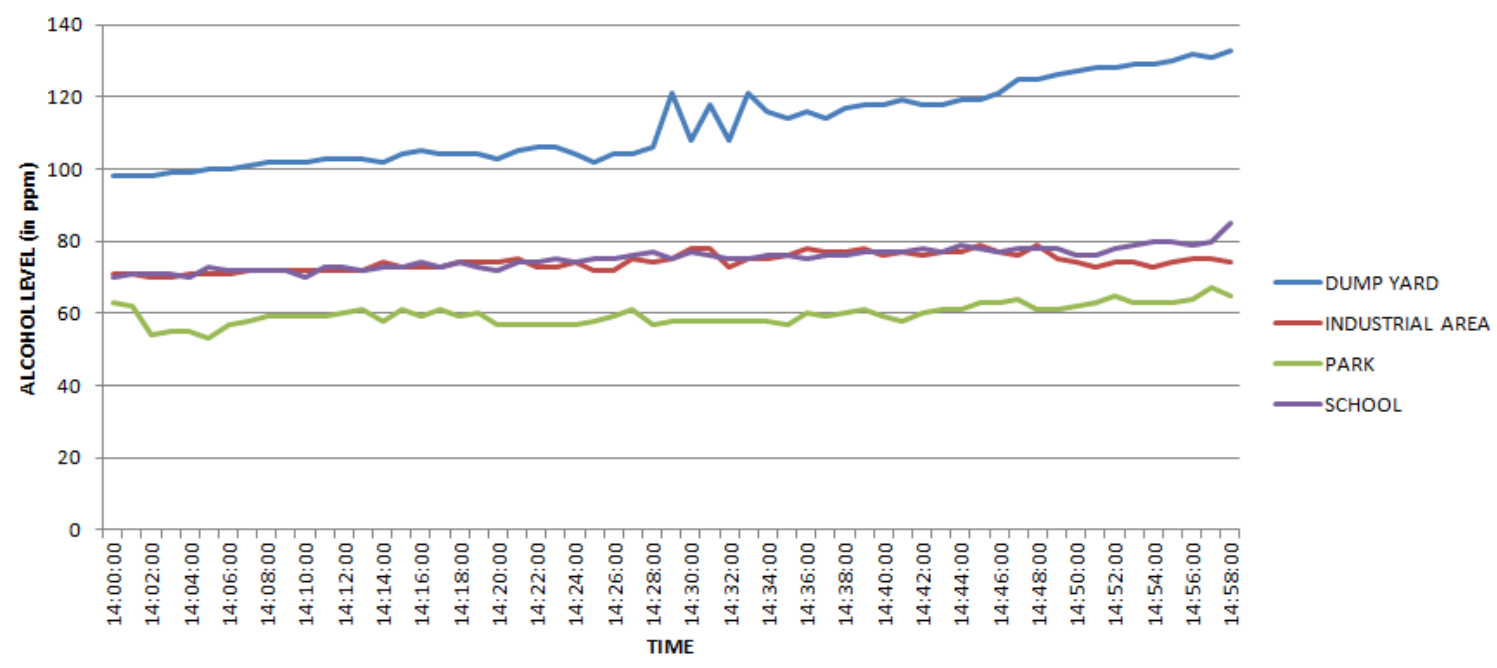

Graph 3: Alcohol Level Indication by A1 sensor for the four monitored places 


\subsection{Dumping Yard}

One of the busy dump yards at Rajouri Garden was monitored. The ppm levels were in higher range indicating polluted surroundings.

This indicates high methane levels. An increased alcohol level suggests mixing of the hydrocarbons $(\mathrm{HC})$ with other $-\mathrm{OH}$ emitting gasses.

\subsection{Industrial Area}

The industries at the outer edge of Rajouri Garden form one of the largest industrial places in Delhi, India.

The industries are the main source of pollution apart from vehicular pollution. Thus, any industrial area is supposed to be high on pollution level indicating a poor air quality index. Same has been the recorded case.

\subsection{Park}

The air quality at the park as well as alcoholic levels were in limits during monitored hour thus indicating Parks and Gardens as go to places to get respite from pollution.

\subsection{School}

Readings were recorded during the peak hour, that is when school gets dispersed.

It is interesting to see that the air quality near school monitored was in coherence with degraded air quality near industrial areas. It thus shows that during afternoon hours when school gets suspended, the vehicular pollution indeed takes a toll. Such can be extremely hazardous especially for children.

The above analysis indicates the need for regular monitoring of air quality levels and suggesting alternative routes to travelers to keep the pollution control levels in check at a place. Imagine a burst of traffic hopping in front of a school during the afternoon hours when school is getting suspended? Or a traffic jam in front of a dump yard?

The proposed system plays a pivotal role in analyzing such conditions and situations and takes the initiative of informing travelers about a route less polluted, hence the concept of Aware Traveling.

The permissible levels can be suggested by understanding $\mathrm{AQI}$ of the region that has been proposed by the government [21].

\section{CONCLUSION}

This work presents a system design to understand the pollution accumulation levels at various areas of interest and helps structure the readings with help of real-time analytics. Moreover, it can help direct vehicles and pedestrians away from a region, by indicating an alternative route when the pollutant levels cross a threshold, thus helping reduce vehicular pollution and inculcating a healthier traveling practice.

This work looks promising based on the analysis conducted. Besides, the proposed system has come across as a costeffective solution compared to other air monitoring devices and technologies with its most stark functionality being a combination of Internet of Things and Analytics of Things both at the same time.

Therefore, a real-life implementation of this proposed prototype will work as desired and benefit a large number of people to help create a healthier society. It, hence is a smart step in the direction towards creating a SMART CITY [22].

\section{FUTURE SCOPE}

Following the guidelines of proposed system, an open data app can be created which will function as a health planner.

Also, a community web can be created where such data from across cities and various countries can be available, thus, providing a single platform to monitor and analyze air pollution at various locations.

This web platform can act as a beneficial resource for making people aware of their immediate environments and plan things for them.

Also, people can be updated through emails/SMS. For this a database of all people registering for such service can be created and GPS can be used to locate the user. So, when the ppm values in a region cross the permissible levels, an email or SMS is generated and sent to all the users present in that region.

\section{REFERENCES}

[1] Khanna, N. Measuring environmental quality: an index of pollution. Ecological Economics, vol-35(2),pp. 191$202,2000$.

[2] Kumar, G. Epidemiological study on effect of air pollution on human health (adults) in Delhi. Central pollution control board, Ministry of environment and forests, Delhi, India, (Jan. 2012). http://cpcb.nic.in/upload/NewItems/NewItem_188_Epide miological_study_AP_Report.pdf. Accessed: 2016- 0502 .

[3] Scotland's environment web http://www.environment.scotland.gov.uk/getinformed/air/air-quality. Accessed: 2016- 05- 01.

[4] Xing Chen et al. Templating Synthesis of $\mathrm{SnO} 2$ Nanotubes Loaded with $\mathrm{Ag} 2 \mathrm{O}$ Nanoparticles and Their Enhanced Gas Sensing Properties. Adv. Funct. Mater. Advanced Functional Materials, vol-21(11), pp. 20492056, 2011

[5] L.E. Cordova-Lopez, A. Mason, J.D. Cullen, A. Shaw, and A.I. Al-Shamma'a. Online vehicle and atmospheric pollution monitoring using GIS and wireless sensor networks. J. Phys.: Conf. Ser. Journal of Physics: Conference Series, vol- 76, pp. 012-019, January 2007.

[6] Yajie Ma, Mark Richards, Moustafa Ghanem, Yike Guo, and John Hassard. Air Pollution Monitoring and Mining Based on Sensor Grid in London. Sensors, vol- 8(6), pp. 3601-3623, January 2008.

[7] Kavi K. Khedo, Rajiv Perseedoss, and Avinash Mungur. A Wireless Sensor Network Air Pollution Monitoring System. IJWMN International Journal of Wireless \& Mobile Networks, vol- 2(2), pp. 31-45, October 2010.

[8] Psanis C. and Biskos G. A low cost air pollution monitor and its application for measuring vehicular emissions. Proceedings of the 14th International Conference on Environmental Science and Technology Rhodes, Greece, pp.3-5, 2015.

[9] Atzori, L. et al. The Internet of Things: A survey. Computer Networks, vol- 54(15), pp. 2787-2805 , 2010.

[10] Daniele Miorandi, Sabrina Sicari, Francesco De 
Pellegrini, and Imrich Chlamtac. Internet of things: Vision, applications and research challenges. Ad Hoc Networks, vol- 10(7), pp. 1497-1516, 2012.

[11] Huansheng Ning, David G. Belanger, Yinglong Xia, Vincenzo Piuri, and Albert Y. Zomaya. Guest Editorial Special Issue on Big Data Analytics and Management in Internet of Things. IEEE Internet of Things Journal IEEE Internet Things J. , vol- 2(4) ,pp. 265-267, 2015.

[12] D'Ausilio, Alessandro. Arduino: A low-cost multipurpose lab equipment. Behavior research methods, vol- 44(2) , pp. 305-313, 2012.

[13] Banzi, M. and Shiloh, M. Make - Getting started with Arduino: The open source electronics Prototyping platform, second edition. Make:Books/O'Reilly, United States, 2015.

[14] ElShafee, Ahmed, and Karim Alaa Hamed. Design and implementation of a WIFI based home automation system. World academy of science, engineering and technology, vol- 68, pp. 2177-2180, 2012.

[15] Lung, C., et al. Wireless data acquisition system for IoT applications. Carpathian Journal of Electronic and Computer Engineering, vol- 6(1), pp.64, 2013.

[16] IoT platform - thethings.Io. 2016 . http://thethings.io. Accessed: 2016- 06- 14.

[17] National Air Quality Index. Central pollution control board (2015).

[18] http://www.cpcb.nic.in/FINAL-REPORT_AQI_.pdf. Accessed: 2016- 05- 07.

[19] Paolo Neirotti, Alberto De Marco, Anna Corinna Cagliano, Giulio Mangano, and Francesco Scorrano. Current trends in Smart City initiatives: Some stylised facts. Cities, vol- 38 , pp. 25-36, 2014. 